\title{
Effect of Etching Parameter on Pore Size and Porosity of Electrochemically Formed Nanoporous Silicon
}

\author{
Pushpendra Kumar and Patrick Huber \\ Faculty of Physics and Mechatronic Engineering, Saarland University, 66041 Saarbrücken, Germany
}

Received 26 December 2006; Accepted 4 April 2007

Recommended by Rakesh K. Joshi

The most common fabrication technique of porous silicon (PS) is electrochemical etching of a crystalline silicon wafer in a hydrofluoric (HF) acid-based solution. The electrochemical process allows for precise control of the properties of PS such as thickness of the porous layer, porosity, and average pore diameter. The control of these properties of PS was shown to depend on the HF concentration in the used electrolyte, the applied current density, and the thickness of PS. The change in pore diameter, porosity, and specific surface area of PS was investigated by measuring nitrogen sorption isotherms.

Copyright ( $) 2007$ P. Kumar and P. Huber. This is an open access article distributed under the Creative Commons Attribution License, which permits unrestricted use, distribution, and reproduction in any medium, provided the original work is properly cited.

\section{INTRODUCTION}

The increasing use of porous silicon in technological applications such as in light-emitting diodes [1], light testing equipment [2], photoelectric solar batteries [3], gas testing devices [4], microdevices [5], biological testing equipment [6], and in fundamental physics [7] has led to a particular rich area of research regarding its physical and chemical properties. The physical properties of porous silicon are fundamentally determined by the shape, diameter of pores, porosity, and the thickness of the formed porous layer. Depending on the etching parameters, for example current density, HF concentration, or substrate doping type and level, the physical properties of PS can be varied [8]. In addition, when the feature size of the pores of PS is less than a few nanometers, various quantum-size effects occur, which make PS even more fascinating. The well-studied PS morphology can range from spongy microporous (pore size $<10 \mathrm{~nm}$ ) and branchy mesoporous silicon (pore size $10-50 \mathrm{~nm}$ ) to the classical macroporous silicon (pore size $50 \mathrm{~nm}-20 \mu \mathrm{m}$ ). Many theories on the formation mechanisms of PS have been reported since its discovery. Beale et al. [9] proposed that the material in the PS is depleted of carriers and the presence of a depletion layer is responsible for current localization at pore tips where the field is intensified. Smith et al. $[10,11]$ described the morphology of PS based on the hypothesis that the rate of pore growth is limited by the diffusion of holes to the growing pore tip. Unagami [12] postulated that the formation of PS is promoted by the deposition of a passive silicic acid on the pore walls resulting in the preferential dissolution at the pore tips. Alternatively, Parkhutik et al. [13] suggested that a passive film composed of silicon fluoride and silicon oxide is between the PS and the silicon substrate and that the formation of PS is similar to that of porous alumina. Even though the mechanisms were different, almost all the investigators believed that the existence of holes is a prerequisite in proceeding the electrochemical polish or formation of porous silicon. The conditions for the formation of PS on all types of substrates in terms of current density and HF concentrations were reported by Zhang et al. [14], where they have shown that the formation of PS occurring during anodization was found to be dependent on the nature of electrochemical reactions. In this paper, we report the effect of the composition of etching electrolyte and applied current density on physical properties of PS. The results are presented in this paper.

\section{EXPERIMENTAL DETAILS}

PS layers were prepared by electrochemical anodic etching of a highly doped $p$-type $\langle 100\rangle$ oriented silicon substrate with a resistivity of $0.01-0.02 \Omega \mathrm{cm}$. The electrochemical cell was made of Teflon and base plate was made of aluminum. A silicon wafer and a copper current collector were mounted at the bottom of the cell by using an $O$-ring that allowed $8.0 \mathrm{~cm}^{2}$ of the Si surface to be exposed to the homogeneously mixed two 
different concentration electrolytes composed of $4: 6$ and $6: 4$ by volume $48 \%$ hydrofluoric acid: $98 \%$ ethanol, respectively. Prior to each experiment, the Si wafers were ultrasonically cleaned in propanol and acetone. The etching current density $12.5 \mathrm{~mA} / \mathrm{cm}^{2}$ was applied for 7 hours. The PS thus prepared was dried by blowing Ar gas onto it. The thicknesses of the layers determined with an optical microscope were in the range of $300-310 \mu \mathrm{m}$. The electrolyte composition of 3 : 7 by volume $48 \%$ hydrofluoric acid: $98 \%$ ethanol was also used to produce PS. But with this concentration of electrolyte, we were able to produce maximum PS thickness of $30 \mu \mathrm{m}$. The etching of silicon in electrolyte composition of 3 : 7 was limited to a epilayer thickness of $30 \mu \mathrm{m}$, since the porous layer peeled off whenever we tried to reach larger thickness. Therefore, this composition of electrolyte has not further been used for comparison. The prepared PS was then fixed into the homemade all-metal gas handling system that is equipped with a membrane pressure gauge of $1000 \mathrm{mbar}$ full scale to study the physical properties of PS by measuring adsorption/desorption isotherms of $\mathrm{N}_{2}$ in porous silicon at $77.2 \mathrm{~K}$.

\section{RESULTS AND DISCUSSION}

Pores in silicon form during anodic polarization in aqueous HF solution, depending on the electrode potential and HF concentration. Many theories for pore formation mechanism have been reported in the literature [9-14]. In general, the porous silicon formation is considered to result from the inhomogeneous dissolution of the silicon surface due to competing reactions: silicon oxide formation followed by dissolution of the oxide versus a direct dissolution of silicon by HF [15]. The illustrative equation of the overall process during the PS formation can be expressed as follows:

$$
\begin{gathered}
\mathrm{Si}+2 \mathrm{HF}+2 h^{+} \longrightarrow \mathrm{SiF}_{2}+2 \mathrm{H}^{+}, \\
\mathrm{SiF}_{2}+4 \mathrm{HF} \longrightarrow \mathrm{H}_{2}+\mathrm{H}_{2} \mathrm{SiF}_{6} .
\end{gathered}
$$

The etching rate is determined by the holes $\left(h^{+}\right)$accumulation in the adjacent regions of the $\mathrm{HF}$ electrolyte and $\mathrm{Si}$ atoms.

The porous silicon was formed in homogeneously mixed electrolyte composed of 4 : 6 and $6: 4$ by volume $48 \%$ hydrofluoric acid: $98 \%$ ethanol with constant applied etching current density of $12.5 \mathrm{~mA} / \mathrm{cm}^{2}$ for 7 hours. The mesoporous silicon prepared with different concentrations of HF was characterized by nitrogen sorption isotherms. As the change in nanorange cannot be monitored quantitatively by spectroscopic techniques, therefore the determination of the pore size distribution in mesoporous $\mathrm{Si}$ is usually based on the analysis of the sorption isotherms of gases at low temperature by referring to the Brunauer-Emmett-Teller (BET) model for adsorption $[16,17]$. Figures $1(\mathrm{a})$ and $1(\mathrm{~b})$ show the adsorption and desorption isotherms of $\mathrm{N}_{2}$ in mesoporous silicon (prepared with different concentrations of HF) at $77.2 \mathrm{~K}$ (the filling fraction is plotted as function of the reduced vapour pressure $\left.p / p_{0}\right)$. The first part of the curve indicated by the portion $A B$ in Figures $1(\mathrm{a})$ and $1(\mathrm{~b})$ at low relative vapor pressures corresponds to the adsorption of gas on the pore

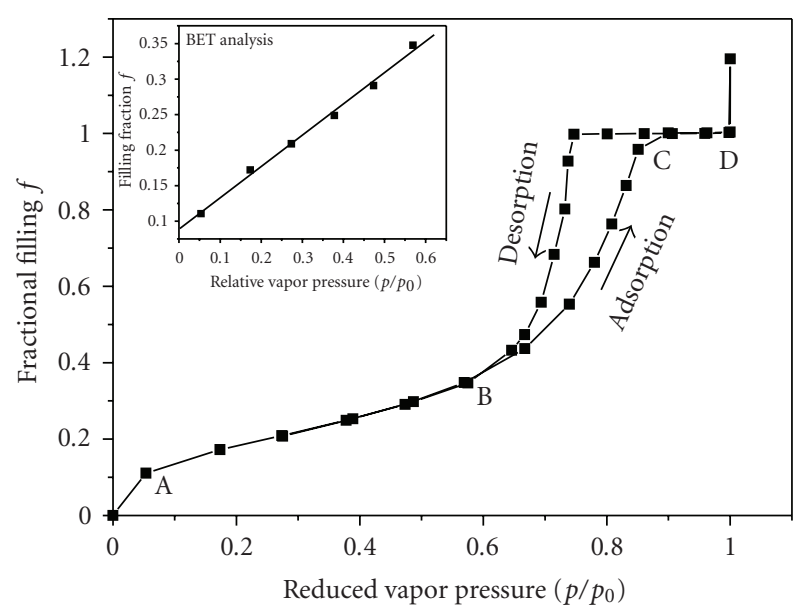

(a)

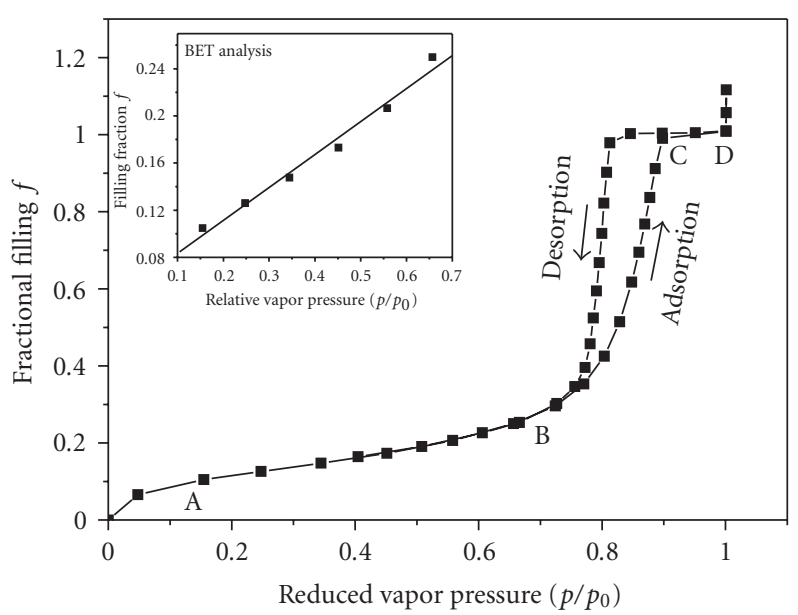

(b)

FIgURE 1: Adsorption \desorption isotherms of $\mathrm{N}_{2}$ at $77.2 \mathrm{~K}$ in PS prepared at different electrolyte compositions: (a) HF : ethanol (6 : 4), (b) HF : ethanol $(4: 6)$. Inset in corresponding figures is the linear fit in the region $\mathrm{AB}$.

wall and allows to determine the total surface area [17]. After the value of volume of nitrogen gas adsorbed on the pore wall is obtained from the isotherm, multiplication of the number of molecules required to form a unimolecular layer by the average area occupied by each molecule on the surface gives the absolute value of the surface area of the adsorbent. The region $\mathrm{AB}$ was linearly fitted to calculate the specific surface area by BET analysis shown in inset of the corresponding Figures 1(a) and 1(b). The sharp increase at higher relative vapor pressures indicated by the portion BC is related to capillary condensation of the gas into the pores, which is used to determine the pore size distribution. The pore size of the PS was calculated using the Kelvin equation [18]. The final plateau indicated by the portion CD shows the complete filling of the pores, and the amount of liquid corresponding to the volume of the gas adsorbed allows the determination of porosity. The hysteresis between adsorption 
and desorption branches is also typical for capillary condensation. The specific surface area, pore diameter, and porosity of mesoporous silicon prepared with different concentrations of HF in electrolyte were determined using different regions of nitrogen isotherm shown in Figures 1(a) and 1(b). The pore diameter and porosity of mesoporous silicon was found to decrease with an increase of the HF concentration in the used etching electrolyte at constant applied current density. The specific surface area increases with decreasing pore diameter. The values are listed in Table 1. The physical properties of PS are determined by two large groups of factors, those that affect carrier density on the surface of a pore bottom and those that affect only the distribution of the reactions. The first group of factors includes doping type and concentration and potential. The second group of factors includes current density and HF concentration. In this report, we have varied the HF concentration and all other parameters were kept constant. On the basis of collected information from the literature [9-14], the decrease of pore diameter and porosity with increase of HF concentration in etching electrolyte can be understood as follows: for highly doped $p$-type $\mathrm{Si}$, both the pore diameter and wall thickness are largely determined by the thickness of the space-charge layer formed at the interface of electrolyte and Si. Thus, in general, pore diameter has the same order of magnitude as the thickness of the space-charge layer. The wall thickness is generally less than twice the space-charge layer thickness. Because of the overlapping of the two space-charge regions entering at neighboring pores, the wall region is depleted of carriers and is thus not conductive. If the wall thickness is larger than twice the space-charge layer thickness, the walls are not depleted of carriers and dissolution can still occur to form new pores on the walls. For a PS formed for controlled space-charge layer thickness, the actual wall thickness depends on the relative dissolution rates between the edge of a pore bottom $\left(i_{b}\right)$ and the pore tip $\left(i_{t}\right)$. If $i_{b}$ is comparable to $i_{t}$, significant dissolution occurs at the edge of the pore bottom before the pore tip propagates far away. This results in a thin wall or the annihilation of walls. On the other hand, if $i_{b}$ is very small compared to $i_{t}$, the pore tip propagates relatively fast so that before much dissolution occurring on the edge of the pore bottom, the edge has already moved into the wall region where dissolution is virtually stopped due to lack of carriers. This generates relatively thick walls and small pore. For $p$-Si, increasing HF concentration reduces the thickness of the space-charge layer and increases the pore tip current density, which results in smaller pores and thicker wall. On the other hand, polishing of silicon in aqueous HF solution is known to be preceded by silicon oxide formation. The oxide is then dissolved by HF through formation of a fluoride complex in the solution. The dissolution rate of silicon oxide increases with increasing HF, which in turn increases the critical current density at which the surface is covered by oxide. As a result, the pores become smaller and walls become thicker with increasing HF concentration [15, 19]. Figure 2 shows the variation of PS layer thickness and porosity with etching time at constant current density of $12.5 \mathrm{~mA} / \mathrm{cm}^{2}$. The thickness and porosity of porous layer increase linearly with
TABLE 1: Variations of pore diameter, porosity, and specific surface area of PS with electrolyte composition at constant current density of $12.5 \mathrm{~mA} / \mathrm{cm}^{2}$.

\begin{tabular}{ccccc}
\hline HF & Ethanol & Pore dia. $(\mathrm{nm})$ & Porosity $(\%)$ & Specific surface area \\
\hline 4 & 6 & 10 & 50 & 500 \\
6 & 4 & 6 & 40 & 710 \\
\hline
\end{tabular}

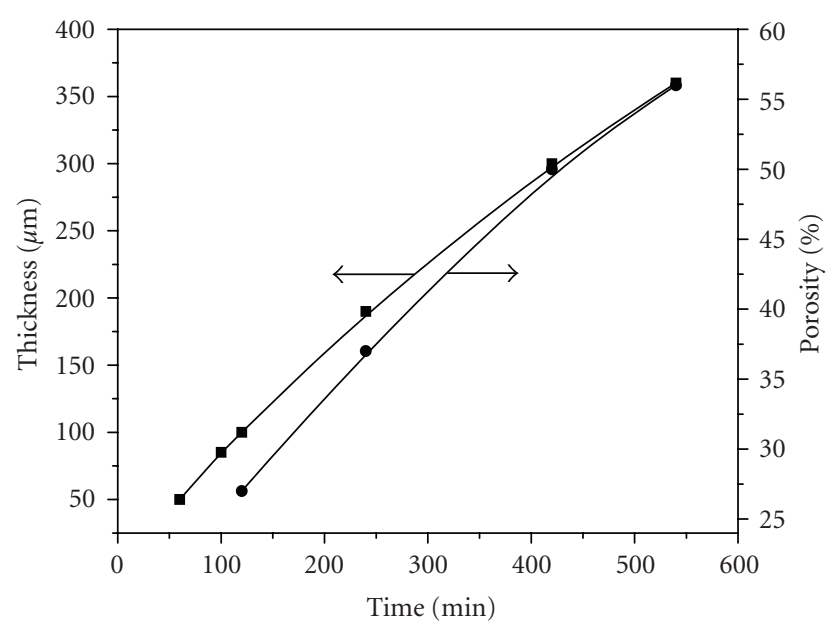

FIGURE 2: Variation of porous layer thickness and porosity with etching time at constant applied current density of $12.5 \mathrm{~mA} / \mathrm{cm}^{2}$.

etching time. It is believed that this variation in porosity with thickness is related to the chemical dissolution of the porous material during formation. During the electrochemical reaction, and as a function of the anodizing time, the effect of the chemical dissolution is to increase the average porosity and pore radii. PS was etched for one hour at different current densities and it was found that the thickness of PS layer is linearly varying with the applied current density shown in Figure 3.

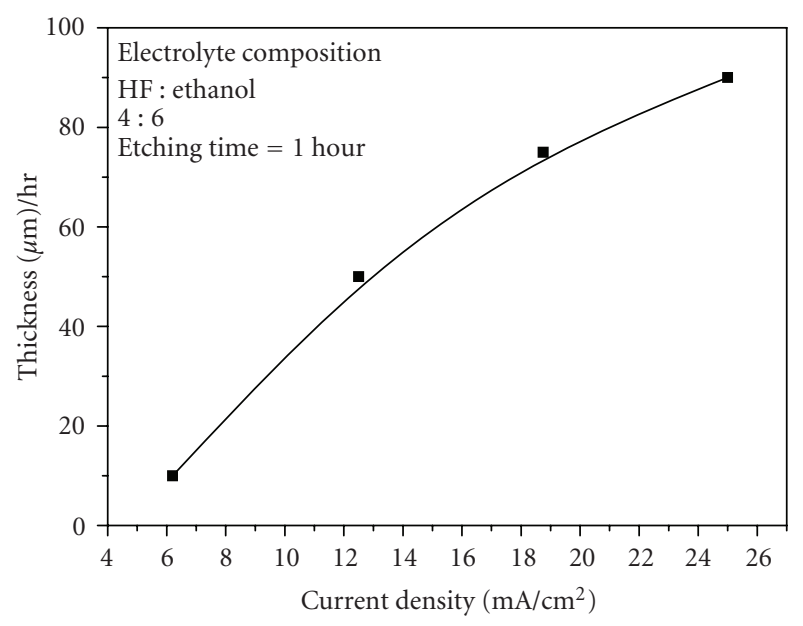

FIGURE 3: Variation of porous layer thickness with different constants applied current density for 1 hour. 


\section{CONCLUSIONS}

Electrochemically etched mesoporous silicon formed in homogenously mixed electrolyte of HF and ethanol was characterized by nitrogen sorption isotherms at $77.2 \mathrm{~K}$, revealing that the concentration of HF in etching electrolyte plays a crucial role in controlling the physical properties of PS. It was found that the pore diameter of $10 \mathrm{~nm}$ and porosity of $50 \%$ of PS prepared in 4HF : 6 ethanol decreased to pore diameter of $6 \mathrm{~nm}$ and porosity of $40 \%$ of PS prepared in $6 \mathrm{HF}: 4$ ethanol. The etching time has been found to vary both the porosity and the thickness of PS.

\section{ACKNOWLEDGMENTS}

Part of this work has been supported within the DFG priority Program 1164, Nano- and Microfluidics, Grant no. Hu $850 / 2$.

\section{REFERENCES}

[1] A. Richter, P. Steiner, F. Kozlowski, and W. Lang, "Currentinduced light emission from a porous silicon device," IEEE Electron Device Letters, vol. 12, no. 12, pp. 691-692, 1991.

[2] G. Smestad, M. Kunst, and C. Vial, "Photovoltaic response in electrochemically prepared photoluminescent porous silicon," Solar Energy Materials and Solar Cells, vol. 26, no. 4, pp. 277 283, 1992.

[3] G. Willeke, H. Nussbaumer, H. Bender, and E. Bucher, "A simple and effective light trapping technique for polycrystalline silicon solar cells," Solar Energy Materials and Solar Cells, vol. 26, no. 4, pp. 345-356, 1992.

[4] J. P. Proot, C. Delerue, and G. Allan, "Electronic structure and optical properties of silicon crystallites: application to porous silicon," Applied Physics Letters, vol. 16, no. 16, pp. 1948-1950, 1992.

[5] V. Lehmann, "Developments in porous silicon research," Materials Letters, vol. 28, no. 4-6, pp. 245-249, 1996.

[6] A. Janshoff, K.-P. S. Dancil, C. Steinem, et al., "Macroporous p-type silicon fabry-perot layers. Fabrication, characterization, and applications in biosensing," Journal of the American Chemical Society, vol. 120, no. 46, pp. 12108-12116, 1998.

[7] D. Wallacher, N. Künzner, D. Kovalev, N. Knorr, and K. Knorr, "Capillary condensation in linear mesopores of different shape," Physical Review Letters, vol. 92, no. 19, Article ID 195704, 4 pages, 2004.

[8] R. Herino, G. Bomchil, K. Barla, C. Bertrand, and J. L. Ginoux, "Porosity and pore size distributions of porous silicon layers," Journal of the Electrochemical Society, vol. 134, no. 8, pp. 1994 2000, 1987.

[9] M. I. J. Beale, J. D. Benjamin, M. J. Uren, N. G. Chew, and A. G. Cullis, "An experimental and theoretical study of the formation and microstructure of porous silicon," Journal of Crystal Growth, vol. 73, no. 3, pp. 622-636, 1985.

[10] R. L. Smith and S. D. Collins, "Porous silicon formation mechanisms," Journal of Applied Physics, vol. 71, no. 8, pp. R1-R22, 1992.

[11] R. L. Smith, S. F. Chuang, and S. D. Collins, "A theoretical model of the formation morphologies of porous silicon," Journal of Electronic Materials, vol. 17, no. 6, pp. 533-541, 1988.

[12] T. Unagami, "Formation mechanism of porous silicon layer by anodization in HF solution," Journal of the Electrochemical Society, vol. 127, no. 2, pp. 476-483, 1980.
[13] V. P. Parkhutik, L. K. Glinenko, and V. A. Labunov, "Kinetics and mechanism of porous layer growth during n-type silicon anodization in HF solution," Surface Technology, vol. 20, no. 3, pp. 265-277, 1983.

[14] X. G. Zhang, S. D. Collins, and R. L. Smith, "Porous silicon formation and electropolishing of silicon by anodic polarization in HF solution," Journal of the Electrochemical Society, vol. 136, no. 5, pp. 1561-1565, 1989.

[15] X. G. Zhang, "Morphology and formation mechanisms of porous silicon," Journal of the Electrochemical Society, vol. 151, no. 1, pp. C69-C80, 2004.

[16] G. Bomchil, R. Herino, K. Barla, and J. C. Pfister, "Pore size distribution in porous silicon studied by adsorption isotherms," Journal of the Electrochemical Society, vol. 130, no. 7, pp. 1611-1614, 1983.

[17] S. Brunauer, P. H. Emmett, and E. Teller, "Adsorption of gases in multimolecular layers," Journal of the American Chemical Society, vol. 60, no. 2, pp. 309-319, 1938.

[18] Y. C. Yortsos, in Methods in the Physics of Porous Media, P. Wong, Ed., chapter 3, p. 69, Academic Press, San Diego, Calif, USA, 1999.

[19] H. Föll, J. Carstensen, and S. Frey, "Porous and nanoporous semiconductors and emerging applications," Journal of Nanomaterials, vol. 2006, Article ID 91635, 10 pages, 2006. 

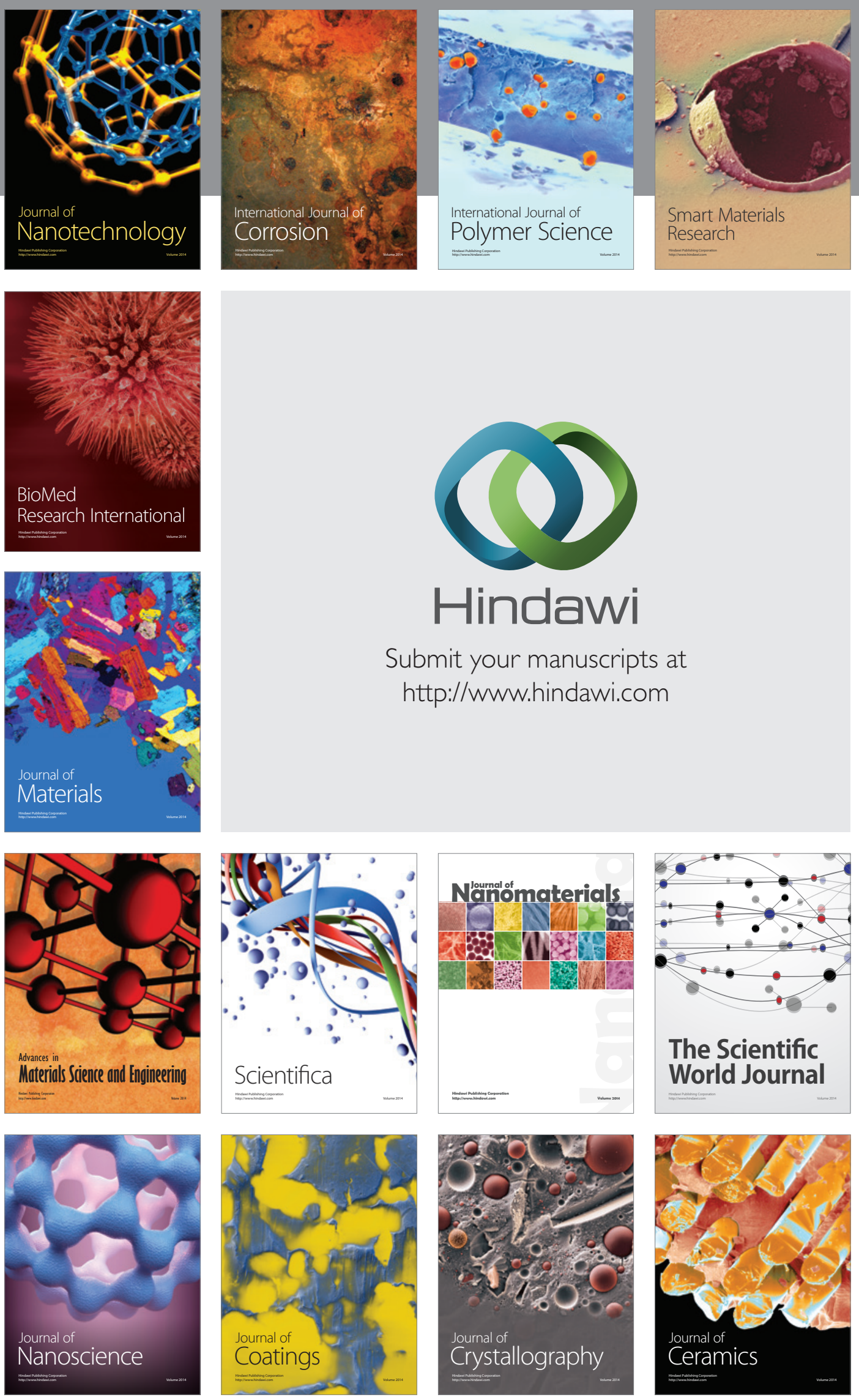

The Scientific World Journal

Submit your manuscripts at

http://www.hindawi.com

\section{World Journal}

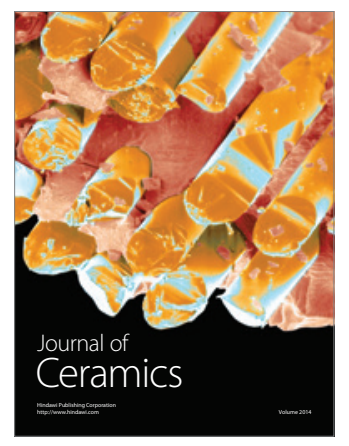

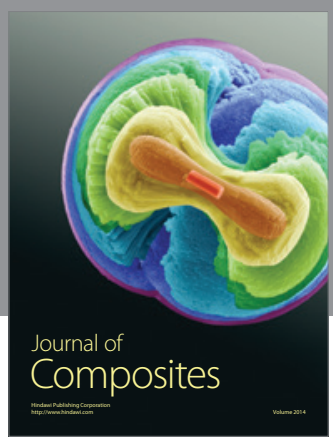
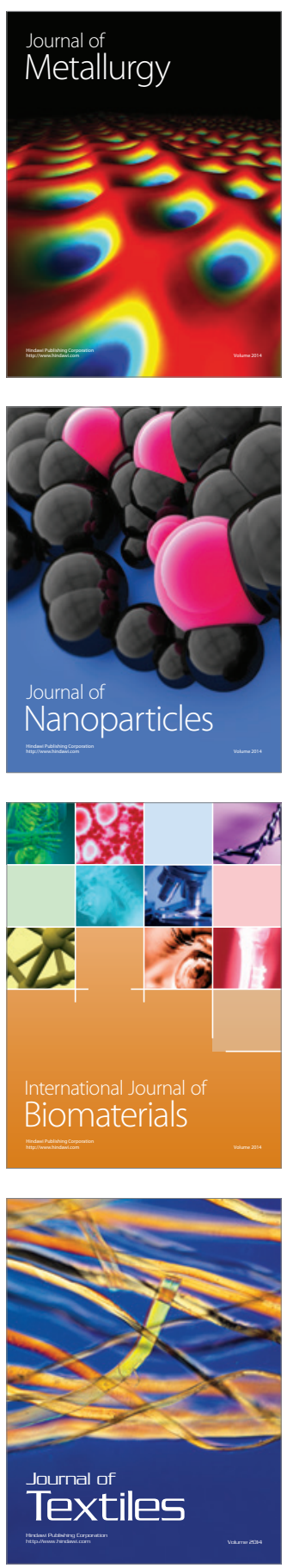